\title{
SNPlotz: a generic genome plot tool to aid the SNP association studies
}

\author{
Zhi-Liang Hu*, Rex Fernando, Dorian Garrick, James M Reecy
}

From UT-ORNL-KBRIN Bioinformatics Summit 2010

Cadiz, KY, USA. 19-21 March 2010

\section{Background}

High throughput SNP genotyping has empowered livestock researchers to perform genome wide association studies to discover genes responsible for complex traits or economically important quantitative traits. The analysis of large numbers of genotypes is not only a challenge for statistical data analysis but also presents a tedious job for users to interpret and comprehend the large number of statistics generated. A simple and fast approach is to plot the phenotypic association values of each SNP against their genome locations. The benefit is twofold: (1) certain genome locations may quickly draw

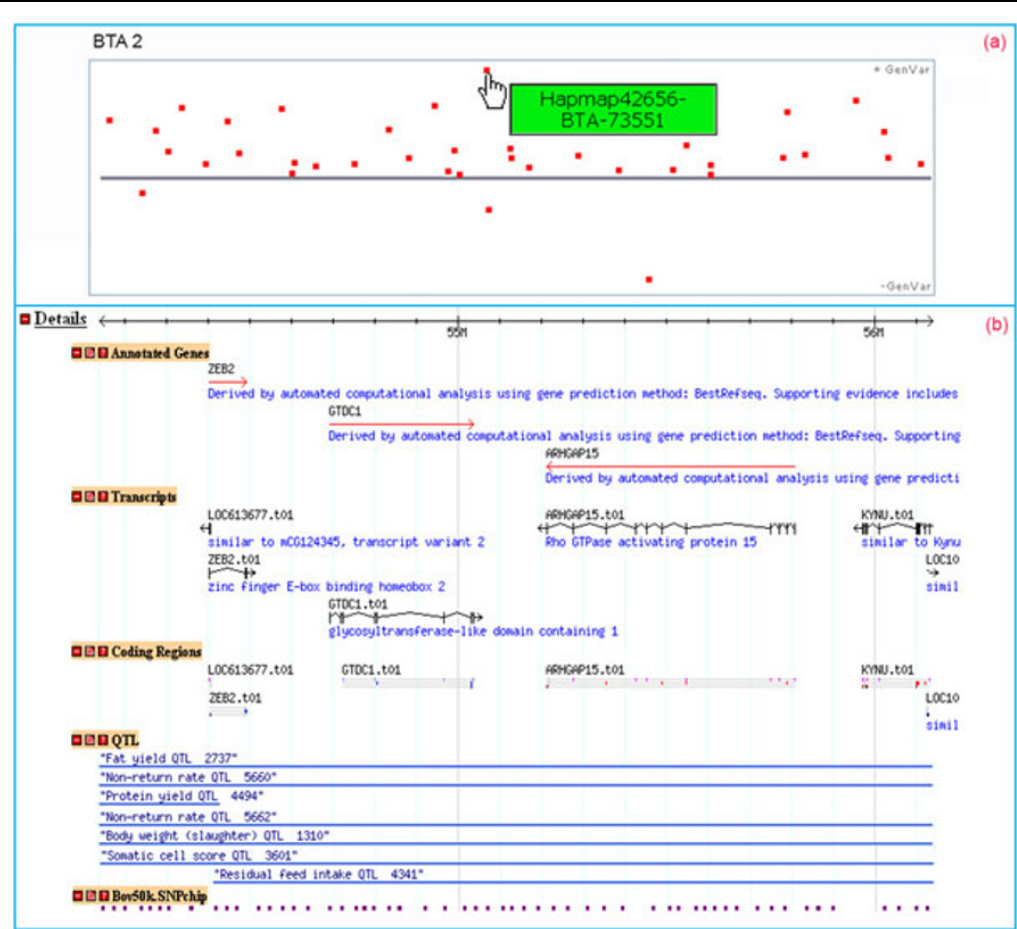

Figure 1 Sample view of SNPLOTz output showing (a) SNP phenotypic value plot on bovine chromosome 2; (b) Interested data point can be linked to GBrowse for alignment with various structural genomics features, such as annotated transcripts and previously mapped QTL etc.

\footnotetext{
* Correspondence: zhu@iastate.edu

Department of Animal Science and Center for Integrated Animal Genomics, lowa State University, Ames, IA 50011, USA
} 
attention if many closely located SNPs are found to show higher degree of associations to traits. (2) It is feasible to locate causal candidate genes when the genome plot is aligned with genomic features such as transcripts, genes, or mapped QTL.

\section{Materials and methods}

We have developed an interactive genome plotting tool, SNPLOTz, for SNP association studies to achieve these goals. The software can plot any values associated with individual SNPs, such as estimates of their effects, with respect to their genome locations. The input data used to prime the design of the tool was from cattle $50 \mathrm{~K}$ and pig 60K SNP chip association studies. The phenotype association analysis data was from Gensel (a software package by Garrick et al.; unpublished data). The tool is designed to take SNP IDs along with any kind of phenotypic association data, find the genomic locations of all SNPs preloaded in the backend MySQL database, and plot them in a two-dimensional graph. The output includes a whole genome plot and individual chromosome plots (Figure 1a). The whole genome plot can give user a quick overall impression, while the chromosome plots are easy for relative location comparisons. Furthermore, the tool also enables dynamic link of each data point to GBrowse [1] to visualize the SNP locations in comparison against other types of genome features such as annotated genes, curated QTL, etc. (Figure 1b). Users can upload as many as 6 data files; each can have as many as 8 columns of phenotype data; either Gensel serial IDs or Illumina SNP IDs may be used. Currently the tool is under further improvement to allow users a private area to store own data for re-use, and to couple with graphic capability of drawing correlation coefficients between any two SNP points for reference. A plan is also on the way to create a Java equivalent program to suit diverse needs of users.

Published: 23 July 2010

\section{Reference}

1. Stein LD, Mungall C, Shu S, Caudy M, Mangone M, Day A, Nickerson E, Stajich JE, Harris TW, Arva A, Lewis S: The generic genome browser: a building block for a model organism system database. Genome Res 2002, 12:1599-610.

doi:10.1186/1471-2105-11-S4-P4

Cite this article as: Hu et al: SNPlotz: a generic genome plot tool to aid the SNP association studies. BMC Bioinformatics 2010 11(Suppl 4):P4.

\section{Submit your next manuscript to BioMed Central} and take full advantage of:

- Convenient online submission

- Thorough peer review

- No space constraints or color figure charges

- Immediate publication on acceptance

- Inclusion in PubMed, CAS, Scopus and Google Scholar

- Research which is freely available for redistribution

Submit your manuscript at www.biomedcentral.com/submit 